\title{
O alargamento da razão na literatura de viagens do século XVI
}

\author{
Maria Helena Nery Garcez ${ }^{1}$ \\ (Universidade de São Paulo)
}

RESUMO: O TEXTO SE CONSTRÓI SOBRE DUAS LINHAS DE REFLEXÃO: DE UM LADO, AS NAVEGAÇÕES E OS DESCOBRIMENTOS ALARGARAM OS LIMITES DA RAZÃO; POR OUTRO, DILATARAM OS LIMITES DA MELANCOLIA OCIDENTAL. LUZES E SOMBRAS FICARAM DOCUMENTADAS EM: OS LUSÍADAS E PEREGRINAÇÃO. DEFENDE-SE NO TEXTO SER MAIS APROPRIADO CONSIDERAR O POEMA CAMONIANO UMA EPOPÉIA MANEIRISTA E A SELVA DE AVENTURAS DE MENDES PINTO UM RELATO OU NOVELA PICARESCA. CONCLUSÃO: SE DEPOIS DAS NAVEGAÇÕES A CIÊNCIA AVANÇOU, NA FILOSOFIA PASCAL (SÉC. XVII) INICIARÁ O PENSAMENTO TRÁGICO MODERNO.

ABSTRACT: THE TEXT PRESENTS TWO LINES OF REFLECTION: IF THE LIMITS OF REASON WERE ENLARGED BY THE NAVIGATIONS AND DISCOVERIES, IN THE OTHER SIDE, THE MELANCHOLY OF THE OCCIDENTAL WORLD INCREASED AND BECAME MORTALLY DEEPER. THESE LIGHTS AND SHADOWS WERE DOCUMENTED IN: OS LUSÍADAS AND PEREGRINAÇÃO. THE TEXT PROPOSES THAT THE CAMONIAN POEM MUST BE DEFINITIVELY CONSIDERED A MANNERIST EPIC POEM AND MENDES PINTO'S ADVENTURES A PICARESQUE NOVEL. CONCLUSION: IF AFTER THE NAVIGATIONS THE SCIENCE DEVELOPED, IN PASCAL'S PHILOSOPHY (XVIITH CENTURY) WILL START THE MODERN TRAGIC.

PALAVRAS-CHAVE: NAVEGAÇÕES: RAZÃO E MELANCOLIA - OS LUSÍADAS E PEREGRINAÇÃO: CLASSIFICAÇÃO - NAVEGAÇÃO: PENSAMENTO TRÁGICO.

KEY-WORDS: NAVEGATIONS: REASON AND MELANCHOLY - OS LUSÍADAS E PEREGRINAÇÃO: CLASSIFICATION - NAVEGATIONS: TRAGIC THOUGHT.

1 Professora Titular de Literatura Portuguesa da USP. 
rincípio evocando o dito: Enquanto você estuda a magia, a magia estuda você. Curiosa frase, que aponta para uma recíproca relação de forças, quando os elementos postos em contacto não são inertes, sejam elas crenças, povos, ideologias ou estratégias políticas. Esse tipo de relação nos leva a perguntar: quem, afinal, é objeto de quem? A magia parece ser o objeto de quem a estuda, o estudioso parece ser o sujeito dessa relação e dominá-la. Durante o processo, porém, ele pode não ser invulnerável à força e/ou ao fascínio do estudado, de modo que a pretensa superioridade com a qual dela se aproximara pode demonstrar-se apenas isso, uma pretensa superioridade. Se ele não sai ileso - e isso é o provável - é porque a magia também exerce domínio sobre ele. Esse tipo de relação é bem conhecido dos analistas, por exemplo, sempre envolvidos, como estão, em processos de análise de outros eus.

Posto isso, procuremos, agora, fazer a transferência dessa relação de forças para os povos dos séculos XV e XVI, época que, para nós, leitores, é de atraente e fácil acesso por ter ficado consignada em dois monumentos literários portugueses, Os Lusíadas (1 $1^{\mathrm{a}}$ ed. 1572) e Peregrinação, de Fernão Mendes Pinto ( $1^{\mathrm{a}}$ ed. 1614 , mas escrita no século XVI, relatando viagens e aventuras desse mesmo século).

Então, em Os Lusíadas não é possível ver que aquele que parte em busca de descobertas, conquistas e novos mundos, não é também enquanto descobre e conquista - embora não exatamente do mesmo modo e/ou no mesmo momento - descoberto e, por sua vez, conquistado? A Fé e o Império, que o "cume da cabeça de Europa toda" (CAMÕES, 1985: III, 20) quis expandir foi via de mão única ou essa via, de muitos modos, se foi convertendo em via de mão dupla e essa "Europa toda", no decorrer do tempo, também não foi sendo, e ainda o continua, "devastada" pelas assim chamadas "terras viciosas de África e de Ásia?” (CAMÕES, 1985, III, 20). As relações entre esses povos e respectivas culturas não se demonstraram e continuam a demonstrarem-se recíprocas, mútuas, reversíveis?

Os Lusíadas e a Peregrinação documentam - fartamente - o quanto a razão humana foi obrigada a alargar seus limites em decorrência das navegações e das descobertas. Em ambas as obras abundam advérbios e adjetivos intensificadores como "tão", "tanto", "tanto... quanto", "tamanho”, "quamanho”, "muito”, "novos", "copiosos", "numerosos"; substantivos como "espanto", "feitos", 
"novidades", maravilha", "milagre", "colosso", "prodígio", "assombro"; verbos como "ver", "ouvir", "contar", "descobrir"; narrações e descrições que se caracterizam pela profusão de coisas novas, parecendo, certas páginas da Peregrinação, cornucópias a despejarem a abundância de seus frutos e, numerosas estâncias de Os Lusíadas, incessantes marés de informações de geografia humana, econômica e de história sobre as mais remotas paragens do mundo então conhecido, condensadas, muitas vezes, em brevíssimos epítetos.

Nunca será demais reconhecer, então, que essas obras são, literária e historicamente, monumentais. Elas só bastariam para tornar grande uma literatura e trazem consigo a complexidade da relação de forças do momento de que tratamos. Avancemos.

Os Lusíadas se querem uma epopéia clássica e têm de pagar esse tributo. Mas será que são? Deixemos, por ora, essa pergunta, a que depois voltaremos. A Peregrinação, não tendo compromisso "explícito" com poética alguma - embora tenha, evidentemente, uma poética - é mais livre. Curioso é observar, olhando o poema camoniano com olhos de hoje, que o que talvez fosse atraente e "moderno" para o gosto humanista, como a armação mitológica, a nós pareça menos aliciante do que os relatos da viagem com suas peripécias e vicissitudes.

Não apenas Von Humboldt admirava a descrição da tromba marítima - fenômeno ainda não esclarecido pela ciência seiscentista - que o Gama fez ao rei de Melinde. Essa descrição, inserida no relato de outras "cousas do mar, que os homens não entendem" (CAMÕES, 1985: V, 16), despertou e continua despertando o entusiasmo de gerações de leitores do poema, entre os quais, com várias turmas de alunos, me incluo eu.

As "cousas do mar, que os homens não entendem", como a tromba marítima, o "fogo-de-santelmo" ou "lume vivo" e o relato da "doença crua e feia, a mais que eu nunca vi” (CAMÕES, 1985: V, 81), não só foram êxitos poéticos, mas constituíram importantes registros dos desafios que os novos fenômenos observados e vividos pelos navegantes trouxeram aos estudiosos da época. O poema camoniano, embora com brevidade, teve a sutileza de documentar a decisiva e candente querela entre o saber empírico e o livresco que, em decorrência desses fenômenos, foi-se travando cada vez com maior força. O embate ficou admiravelmente sintetizado no irônico repto lançado por Vasco da Gama, nos versos com que finaliza a descrição da tromba marítima: "Vejam agora os sábios na escritura, / Que segredos são estes da 
natura" (CAMÕES, 1985: V, 22).

A razão desafiada teve de voltar a valorizar o conhecimento sensorial e buscar a explicação racional para os fenômenos claramente vistos, que também não tinham sido notórios nem a "Ptolomeu, Pompônio, Estrabo, Plínio, e quantos passaram" (CAMÕES, 1985: V, 50). É exatamente no canto central do poema, o V, e nele, na estrofe central do canto, a 50, que, em homologia com o feito português de passar o Cabo das Tormentas - para Luís de Camões, o feito central da História, o marco da transição do mundo antigo para o moderno - e, nessa passagem, unir Ocidente e Oriente, que Luís de Camões coloca na boca do gigante Adamastor - alegoria do terrível obstáculo geográfico que dividia o mundo em duas metades - a declaração da grande façanha portuguesa. Se o objetivo imediato da coroa era dilatar o império e desenvolver interesses comerciais, o feito maior, contudo, o que superou aquela transitoriedade e deixou marcas profundas, foi da ordem do conhecimento: a revelação do "nunca visto promonotório" (CAMÕES, 1985: V, 50), a construção da imagem íntegra do mundo, a revelação de fenômenos que obrigaram a ciência a desenvolver-se e puseram ponto final à tirania de um saber que era só livresco, estéril e autoritário, não-científico, portanto.

Por sua vez, a Peregrinação desvenda-nos a mãos-cheias aspectos nunca vistos das civilizações orientais. Fernão Mendes Pinto, embora não fosse letrado, demonstra, em suas narrações e descrições, enorme poder de observação, acuidade notável. Nas páginas da Peregrinação, o homem dos inícios do XVII pôde conhecer as muralhas da China, a admirável descrição da cidade de Pequim, costumes de diferentes povos, sua organização social, nível de civilização e de etiqueta, às vezes superior ao dos ocidentais, suas religiões, guerras e modos - bastante cruéis - de tratar e de punir os prisioneiros. Com esse pícaro narrador que, a dado momento, sob o influxo do místico São Francisco Xavier, se converte, desembarcamos no Japão, assistimos aos debates que o rei do Bungo promove, em sua corte, entre o santo e os bonzos budistas e às andanças e pregações do santo por Índia, Malaca e Japão.

O saber empírico indubitavelmente avançou e, posteriormente, deu lugar ao experimental. A razão dos "Portugueses do Ocidente" que iam buscando as terras do Oriente (CAMÕES, 1985: I, 50) - e com ela a razão do homem europeu - indubitavelmente, alargou-se. Mas, e principiamos agora a tratar da contrapartida, no decorrer de todo esse longo processo, a esses descobri- 
dores, navegantes, comerciantes, administradores, missionários, funcionários, colonizadores e aventureiros, não lhes terá acontecido, como ao Gama, de quem mais de uma vez se afirma: "não lhe sucedeu como cuidava" (CAMÕES, 1985: I, 44; II, 70)? Embora esse verso, se não erro, ocorra apenas duas vezes no poema, não será ele emblemático? Afinal, o que teria sido mais encontrado pelos que embarcaram? Tudo "nos conformes" ou incessantes imprevistos? mais ação ou mais paixão? facilidades ou empecilhos? O que vamos vendo em Os Lusíadas é que, mal concluído o Concílio dos Deuses, principia o relato dos imprevistos e que, no léxico do poema, começam a repetirem-se termos como "engano", "traição", "veneno", "cilada”, "perfídia”, "nefando", "fingido", "duvidoso", "incerto", "mudança".

"No Olimpo luminoso", onde "em luzentes assentos marchetados de ouro e de perlas" os deuses se assentavam como "a razão e a ordem concertavam" (CAMÕES, 1985: I, 23), o que rege é a luminosa e racional convenção renascentista, enquanto no Atlântico e Índico, o que rege é a sempre cambiante realidade marítima, onde "tudo são mudanças" (CAMÕES, 1985: V, 66) e os embates com os habitantes locais. A voz épica então vai abandonando o discurso ufano e cristalino e - o que causa espanto ao leitor, pois ainda no canto I, isto é, cedo demais - vai assumindo um discurso sombrio, semelhante ao das lamentações do Livro Jó, em que mesmo o Deus cristão é questionado.

O recado que trazem é de amigos, Mas debaixo o veneno vem coberto; Que os pensamentos eram de inimigos, Segundo foi o engano descoberto. Ó grandes e gravíssimos perigos! Ó caminho da vida nunca certo! Que aonde a gente põe sua esperança, Tenha a vida tão pouca segurança!
No mar tanta tormenta e tanto dano, Tantas vezes a morte apercebida! $\mathrm{Na}$ terra tanta guerra e tanto engano, Tanta necessidade aborrecida!... Onde pode acolher-se um fraco humano? Onde terá segura a curta vida, Que não se arme e se indigne o céu sereno Contra um bicho da terra tão pequeno? (CAMÕES, 1985, I, 105, 106)

Esse discurso disfórico, mal findas as estâncias introdutórias e principiada a narração, irá progressivamente dividir e disputar o espaço com o eufórico, ao longo de todo o poema. E ao leitor vai sendo dado ver a resposta dos 
"mares nunca dantes navegados", pois não impunemente os "barões assinalados", seus marinheiros e demais comandados "passaram ainda além da Taprobana" (CAMÕES, 1985: I, 1).

Vê também não serem apenas os habitantes locais a apresentarem duas camadas: uma aparência de amizade encobrindo o veneno (os leitores vêem ser esse um comportamento mútuo, pois os recém-chegados não tinham vindo exatamente para fazer beneficência...). Toda a realidade parece ser vista, então, pela voz épica, como um enorme engano, como aparência traiçoeira, não restando absolutamente nenhum refúgio ou ponto de apoio merecedor de confiança. A estância 106, do canto I, contrariando a eloqüente manifestação de fé cristã das estâncias iniciais, aponta duplicidade no próprio Deus, apresentado como "céu sereno", que se arma e se indigna "contra um bicho da terra tão pequeno" (o negrito é meu). Essa mesma menção crítica à Divindade reaparecerá no canto $\mathrm{V}$, quando o Gama principia a relatar “a doença crua e feia" que matou muitos de seus marinheiros: "Assim no céu sereno se dispensa:/ Com esta condição pesada e dura/ Nascemos: o pesar terá firmeza,/ Mas o bem logo muda a natureza" (CAMÕES, 1985: V, 80).

Se até a criticar Deus, visto na cruel indiferença de um "céu sereno", se atreve o discurso camoniano, como estranhar que ele seja sensível à confusão de Babel que, no encontro com os habitantes da costa oriental africana, ele constata? Assim, fica registrado que, chegados a uma pequena ilha e, ao fazerem, em "arábica língua", as tradicionais perguntas épicas, ouvem a seguinte resposta:

Somos, (um dos das ilhas lhe tornou)

Estrangeiros na terra, lei e nação;

Que os próprios são aqueles que criou

A natura, sem lei e sem razão.

Nós temos a lei certa que ensinou

O claro descendente de Abrahão,

Que agora tem do mundo o senhorio;

A mãe Hebrea teve, e o pai Gentio.

(CAMÕES, 1985: I, 53)

Também naquelas remotas paragens os habitantes já eram "estrangeiros na terra, lei e nação". Os nativos eram considerados pelos vencedores como 
"sem lei e sem razão". Também ali a história mostrava as camadas de povos que se guerreavam e sucediam. (Abro parêntese para perguntar: as afirmações de Hobbes, século XVII: "o homem é o lobo do homem” e "a guerra é de todos contra todos", não teriam nada a ver com esse tipo de experiências?) A surpresa dos portugueses por encontrarem, naquela costa, seguidores de Maomé, foi grande: “Qualquer então consigo cuida e nota/ Na gente e na maneira desusada,/ E como os que na errada seita creram,/ Tanto por todo o mundo se estenderam" (CAMÕES, 1985: I, 57).

A ufania dos "barões assinalados" (CAMÕES, 1985: I, 1), com que a epopéia principiara, vai-se transformando na profunda melancolia do "bicho da terra tão pequeno" (CAMÕES, 1985: I, 106) que, mesmo reconhecendo a conveniência de acometer grandes empresas, de desfraldar velas em busca do progresso, não deixa de ver que o velho do Restelo também tem razão em seu lamento: "mísera sorte! estranha condição!", a da humana geração (CAMÕES, 1985: IV, 104).

A Peregrinação não se pretende epopéia, embora o que nela se narre tenha, sob muitos aspectos, um caráter grandioso e, por isso, partilhe do épico. Narra as vicissitudes de um aventureiro, que sem pretextar nobres ideais, não esconde ter partido de Lisboa para tentar sorte e fazer fortuna. É um relato picaresco em que, através das "viciosas malfeitorias" do narrador e companheiros - que não se pretendem heróis, nem descobridores, nem civilizadores, nem cristianizadores - podemos também ver com nitidez relações entre Ocidente e Oriente.

O eu da enunciação desse imenso e labiríntico relato, embarca, ainda adolescente sob as ordens de um verdadeiro pirata. Realizam saques, roubos, testemunham matanças, tomam partido em escaramuças locais, assistem a cruéis punições de prisioneiros, enganam, mentem, cometem toda a sorte de deslealdades, sofrem naufrágios, prisões, são vendidos como escravos... É exemplar o que acontece quando, sob as ordens de António de Faria, chegam à Ilha de Calempluy, na China, e assaltam uma ermida, guardada pelo ancião Hiticou. Enquanto António de Faria com ele fala da fé cristã, seus companheiros, à socapa e por ordem sua, assaltam os caixões dos defuntos, que continham objetos de prata e riquezas. É exemplar que o Hiticou desmascare Nuno Coelho, dizendo-lhe: "Certo que agora vejo o que nunca cuidey que visse nem ouvisse, maldade por natureza, \& virtude fingida, que he furtar $\&$ 
pregar" (PINTO, 1983: 218).

Ora, o que se esperava da ação portuguesa no Oriente e no mundo era o "aumento da pequena cristandade" (CAMÕES, 1985: I, VI) e não que um ermitão chinês desse lições de religiosidade e de virtude a cristãos. Fica patente que o engano, a hipocrisia, a duplicidade não estavam só nos outros povos, mas também estavam neles. De todos aqueles "cristãos" que embarcavam para o Oriente, o único que realmente convenceu o narrador foi São Francisco Xavier, pois neste não havia dobrez.

$\mathrm{Na}$ Peregrinação não há momentos eufóricos, como no poema camoniano. Os títulos, em sua esmagadora maioria falam de paixão e não de ação, ou, se falam de ações, são ações que resultam em paixão: "Do que passey co rey Bata até que me party para Malaca; Do que passamos os três companheiros...; Do que socedeo a Antonio de Faria”... e assim por diante. Nela se mostra a virtude da fortaleza no aspecto do suportar. Aliás, tanto os protagonistas de Os Lusíadas quanto o da Peregrinação, sob esse prisma, estão mais próximos do da Odisséia do que dos heróis da Ilíada. Enquanto esta é a epopéia da fortaleza na dimensão do atacar, a Odisséia é a epopéia da fortaleza na dimensão do passar, da paciência, do agüentar.

É o momento de questionar-nos, diante do exposto, se teria sido sem motivos que Camões, nas redondilhas "Sôbolos rios que vão por Babilônia" (CAMÕES, 1973: 105) tenha afirmado: "vi o bem suceder mal,/ e o mal muito pior" (CAMÕES, 1973: 106) e, mais adiante, ao referir-se ao mundo, tenha dito: "na terra de dor/ de confusão e d'espanto" (CAMÕES, 1973: 111), ou que seja tão pessimista no soneto "Mudam-se os tempos", em que a marca do imprevisto está presente: "diferentes em tudo da esperança”, ou tão exímio cantor do conflituoso, presente não apenas em seu poema épico, mas em tudo, mormente no mundo dos afetos, ou tão cético a respeito da razão que, ele próprio, ajudou a alargar. Transcrevamos dois sonetos:

Verdade, Amor, Razão, Merecimento, qualquer alma farão segura e forte; porém, Fortuna, Caso, Tempo e Sorte, têm do confuso mundo o regimento.

Efeitos mil revolve o pensamento
Correm turvas as águas deste rio, que as do Céu e as do monte as enturbaram; os campos florecidos se secaram, Intratável se fez o vale, e frio.

Passou o verão, passou o ardente estio, 
e não sabe a que causa se reporte; mas sabe que o que é mais que vida e morte que não o alcança humano entendimento.

Doctos varões darão razões subidas, mas são experiências mais provadas, e por isso é milhor ter muito visto.

Cousas há i que passam sem ser cridas e cousas cridas há sem ser passadas, mas o milhor de tudo é crer em Cristo.

(CAMÕES, 1973: 199) uãs cousas por outras se trocaram; os fementidos Fados já deixaram Do mundo o regimento, ou desvario.

Tem o tempo sua ordem já sabida; o mundo, não; mas anda tão confuso, que parece que dele Deus se esquece.

Casos, opiniões, natura e uso fazem que nos pareça desta vida Que não há nela mais que o que parece.

(CAMÕES, 1973: 168)

Impressiona, ao lê-los, constatar que, se houve um alargamento da razão, indiscutivelmente retratado na literatura de viagens do século XVI e na lírica de Camões, houve também, e fora de dúvida, um alargamento muito profundo da melancolia, da visão sombria, pessimista e desesperançada da realidade. Se a razão foi desafiada para compreender e explicar fenômenos antes desconhecidos e, no decorrer do tempo desincumbiu-se bem do desafio, vemos que, na subjetividade do homem europeu, o balanço da arremetida pelos mares, em busca do V Império, não foi positivo.

O primeiro dos sonetos transcritos, em vez de manifestar euforia pelos avanços, apresenta-nos uma visão sombria acerca das forças que regem o "confuso mundo" e manifesta profunda desconfiança nas explicações científicas, optando por uma saída fideísta. O segundo, por sua vez, reitera a visão de que o mundo é "confuso", e tanto, "que parece que dele Deus se esquece". O mundo como Babel se confirma. Mas, o mais grave ainda é que nele se instaura a dúvida, pondo até mesmo sob suspeição a saída apontada no soneto anteriormente lido: "Casos, opiniões, natura e uso,/ fazem que nos pareça desta vida/ que não há nela mais que o que parece."

A essas alturas, seria necessário explicitar o óbvio? Que Os Lusíadas são uma epopéia maneirista - embora não se costume afirmá-lo tão taxativamente - e que o maneirismo eclodiu na Península Ibérica e, em Portugal, principalmente devido ao empreendimento das navegações? Os Lusíadas são alguma 
luz e sombras, muitas sombras, alguma euforia e muita melancolia, algum ímpeto e muita decepção, alguma ordem renascentista e muita visão de Babel. A Peregrinação, por sua vez, constitui uma selva de aventuras, um emaranhado de percursos, um relato picaresco, outra experiência e descrição de uma Babel que contribuiu - e bastante - para a melancolia ibérica e moderna.

Disse Camões nas redondilhas "vi ao bem suceder mal e ao mal, muito pior". Se, depois das navegações e dos descobrimentos, a ciência avançou e muito, no pensamento filosófico do século XVII, Pascal dará início ao pensamento trágico moderno, que será prosseguido por uma tradição filosófica que passará por Schelling, Kierkegaard, Dostoiévski, Unamuno, Gabriel Marcel, Heidegger, Jaspers, Luigi Pareyson. Embora não se possa creditar o surgimento dos pensadores trágicos apenas aos acontecimentos históricos das navegações, dos descobrimentos e de quanto com eles se relacionou, é inegável que, como resultado de todo esse processo, o mundo ocidental ficou marcado por uma consciência profundamente conflituosa, por uma aguda experiência do mal, que recolocou no primeiro plano da reflexão filosófica uma atormentada e perplexa reflexão sobre o problema do mal, uma visão convulsionada da realidade, concretizada na arte barroca e, mais tarde ainda, em manifestações das artes plásticas, literária, dramática e cinematográfica que, no último século, beiraram o desespero.

\section{Referências Bibliográficas}

CAMÕES, Luís V. de. Os Lusiadas. Edição organizada por Emanuel Paulo Ramos. Porto: Porto Editora, 1985.

Rimas. Texto estabelecido e prefaciado por Álvaro J. C. Pimpão. Coimbra: Atlântida, 1973.

PINTO, Fernão Mendes. Peregrinação. Lisboa: Imprensa Nacional; Casa da Moeda, 1983. 